\title{
International Cooperation in Education: The VASSIVIERE Erasmus Intensive Training Program (2011-2013) on Hydrography and Geomatics
}

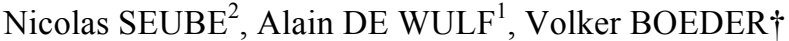 \\ Thomas TOUZE ${ }^{2}$, Nathalie DEBESE ${ }^{2}$, Rodéric MOITIE ${ }^{2}$, Irvin PROBST $^{2}$, \\ Maude Audet MORIN ${ }^{4}$, Timothy NUTTENS ${ }^{1}$, Cornelis STAL ${ }^{1}$. \\ ${ }^{1}$ Ghent University (Ghent, Belgium), Department of Geography, 3D Data Acquisition Cluster \\ ${ }^{2}$ ENSTA (Brest, France), Ocean sensing and mapping Lab \\ ${ }^{3}$ HafenCity University (Hamburg, Germany), Lab Marine Geodesy \\ ${ }^{4}$ CIDCO, Rimouski (Québec)
}

Topic L: the hydrographic profession

\section{SUMMARY}

In the framework of the European Union Erasmus Intensive Program which aims at sponsoring intentive courses jointly proposed by european universities, ENSTA Bretagne (France), Ghent University (Belgium) and HCU University (Germany), and the CIDCO (Interdisciplinary Centre for the Development of Ocean Mapping) (Canada), as an associate partner, organised a hydrographic and topographic surveying camp. This project took place in Lake of Vassivière, one of France's largest artificial lakes exploited by EDF, France's global energy company. Five teams of students were tasked to achieve the survey instructions given by EDF like in a real professional context. The main objective was to survey this $10 \mathrm{~km}^{2}$ lake to focus on points of interest like dam infrastructures, ports, bridges and to open navigation channels for a given level of the lake. A survey boat from the ENSTA Bretagne and land survey equipment from all universities have been mobilised for this purpose. The project received sponsorship from the industry (Boskalis, Netherland) which is interested in the concept of educating students at an international level. Both land and bathymetric surveys has been conducted using a large variety of equipments. This paper will analyze the educational benefit of international cooperation in the field of hydrographic and land survey training.

Key words: hydrographic formation, practical training, topo-bathymetric surveys.

\section{INTRODUCTION AND BACKGROUND}

The Erasmus Intensive Program in Hydrography and Geomatics mobilized 43 students, 12 supervisors from three European countries and an associate partner from Canada (CIDCO, Québec). For the first time in Europe, a fieldwork involving a large number of students and international teams was experienced. The aim of this paper is to explain the benefits of this action in order to encourage such international cooperation in the field of hydrographic survey training.

The ENSTA Bretagne in Brest and the HafenCity University in Hamburg offer programs in hydrography and have both recognition from the FIG/IHO/ICA as category A course in Hydrographic surveying. They both offer a two years Master level program in hydrography. Ghent University offers a two years Master program in Land Surveying, which includes a short introduction to Hydrographic surveying.

The ideas underlying this project were to:

1. Give the students an opportunity to learn in an international context by making international teams;

2. Make them work both on hydrographic and land surveying problems and face challenging topobathymetric surveys of infrastructures;

3. Make them use a wide variety of equipments (LiDAR, sonars, TLS, etc.); 
4. Give the students the responsibility of a whole survey, including hydrographic instructions interpretation, survey planning, quality assessment and reporting to the client.

Only last year, Master students were involved in this program because the aim was not to provide a first experience of practical survey but a more comprehensive work filling up the requirements for FIG/IOH/ICA category A hydrographers, namely a capacity to work, plan and report independently in a quite difficult environment.

The Lake of Vassivière environment offers many challenges for survey. The following features enable us to confront the students with difficult situations:

- A low level of the lake due to an exceptional dry weather in France in 2011 (4 meters below the normal level);

- The presence of sediments especially soft mud in some areas;

- A time varying water column environment because of the dam turbine running during the survey;

- Very shallow water areas;

- The presence of infrastructures (dam, water outflow, ports) which required high accuracy and precision surveys;

- The presence of GPS multipath environments due to surrounding woods or bridges and a relatively poor coverage of GPS permanent stations, located at more than $60 \mathrm{~km}$;

- A very long coastline to survey (more than $47 \mathrm{~km}$ );

- The presence of submerged infrastructures (roads, bridges, houses, mills, walls) dated from before than 1951 (date of construction of the dam).

\section{APPROACH}

\subsection{Context of the project}

The Lake of Vassivière is an artificial lake, located in the Creuse district, in the center of France (Figure 1). The lake has an area of $10 \mathrm{~km}^{2}$, with an average depth of 11 meters and a nominal volume of 110 million cubic meters. Hydroelectric installations of Vassivière Lake are operated by EDF, Unité de Production Centre, by a hydraulic plant of $63,7 \mathrm{MW}$. Hydroelectric facilities are located in the northwest part of the lake. A minimum flow of the Vienne River is used to cool down the Civaux nuclear power plant, located $200 \mathrm{~km}$ away from Vassivière. The touristic activities and navigation are managed by the Lake of Vassivière authorities. The creation of the dam in 1951 contributed to increase the tourism activity (coastal footpath and many nautical activities) in the area with an average visitor number of 70000 persons per year.

During summer, EDF have to maintain the lake level between $647 \mathrm{~m}$ and $650 \mathrm{~m}$ in order to guarantee the possibility of nautical activities and the operation of taxi boats, used in order to minimize car traffic around the lake. To face low water levels (the minimum envisioned lake level is $643 \mathrm{~m}$ ) due to climatic changes and to guarantee a minimum flow in the Vienne valley, an accurate bathymetric map is required in order to plan lake infrastructure modifications (ports, channels).

\subsection{Hydrographic instructions}

Hydrographic and topographic instructions were given by EDF and the Vassivière Lake authorities. The main objective of the project was to produce a full coverage high resolution map of the Vassivière Lake. Instructions given by EDF included the survey of specific areas for infrastructures monitoring and navigation purposes. A total coverage at Order 1 (S-44, OHI standards) was done for bathymetric chart and volume computations, and for infrastructures monitoring and navigation purposes, a total coverage at Special Order was conducted. One of the objective was to check for any problems or obstacles to navigation that may exist in case of low rating operation of the reservoir at $643 \mathrm{~m}$. The TPU (Total 
Propagated Uncertainty) imposed by EDF was $15 \mathrm{~cm}$ for a $95 \%$ confidence level and a gridded DTM with cellsize of $1 \mathrm{~m}$ for navigation areas and $0,5 \mathrm{~m}$ for infrastructures areas (dam, outflow).

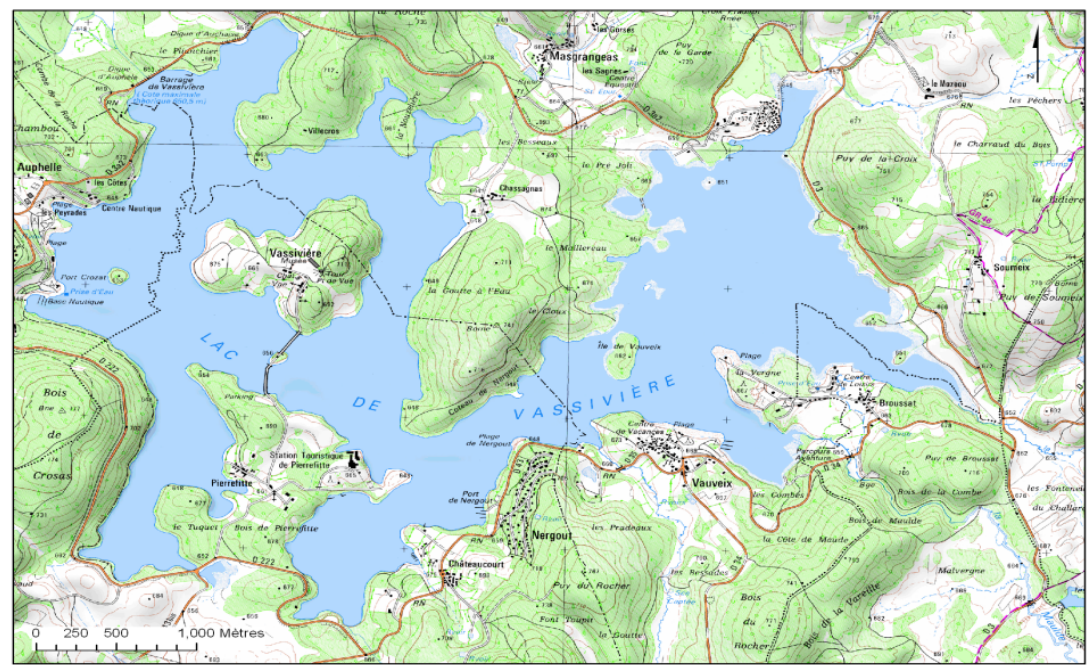

Figure 1: Localisation of Lake of Vassivière, France

\subsection{Fieldwork organization}

During the twelve days of the training, the students were divided into five subgroups, all tasked to perform both bathymetric and topographic survey works. The lake was divided into four survey areas, each area being divided in five subareas, planned to be covered in 2,5 days. During fieldwork, each group had to manage in order to overcome each of the tasks of bathymetry, surveying and data processing. The presence of such a large number of students has maximized the productivity and the data control during the fieldwork. All the data acquired were compared to control points to ensure data accuracy which is a major contribution to hydrographers education.

During the first week of the project, students were assigned to reach a high level of productivity in land surveying. They had to find a way of using the equipment that was allocated (total stations, GPS, TLS) in order to get the most relevant land survey information : data for control points with the 2D laser scanner, data for beach modeling, profiles, etc. Every day, the students had to report the density of topometric point that had surveyed and their quality estimation (Figure 2).
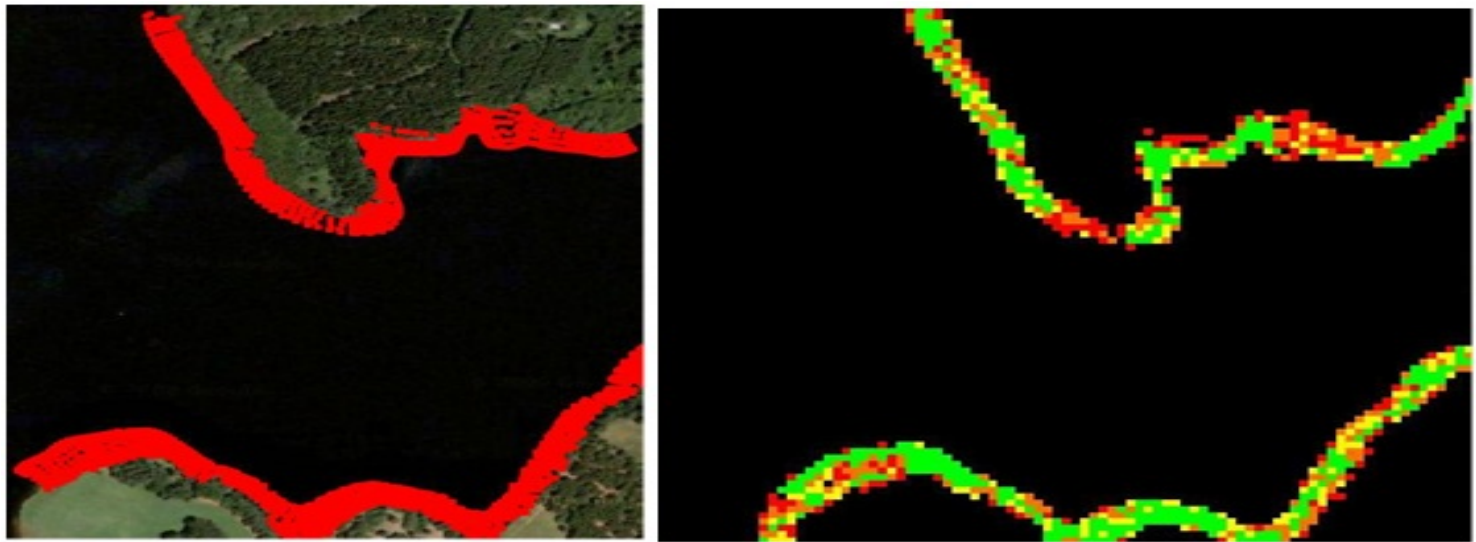


\section{aff organization}

The role of the staff was limited to provide technical assistance for topographic measurement tools, for bathymetric work supervision, for data processing and for coordination of geodetic work. All teams had to manage independently and also had to make daily reports to the staff. Moreover, the staff managed to give a series of lectures on specialized topics.

\section{PROJECT RESULTS}

3.1 Geodesy and positioning

Before the camp, all the benchmarks located around the lake were examined by the staff of the ENSTA Bretagne. Several positioning methods have been used:

- The TERIA permanent RTK network (with limited accuracy due to the fact that the closest base station of the French permanent geodetic network is located $40 \mathrm{~km}$ away from Vassivière), which requires GSM (Global System for Mobile Communications) communication;

- Two base stations installed by students using TERIA RTK averaging;

- Angle and distance measurements by total stations.

The coherence of all position measurements was the first activity planned for the students. Students had the opportunity to study from an experimental point of view the performances of each system to be used during the survey. For the project, three vertical reference systems were considered:

1. GRS80, ellipsoidal heights provided by GPS measurements;

2. IGN69, normal heights (altimetric French official system);

3. NGF-Lallemand, orthometric (old French official system) used by EDF.

The grid RAF09 defining the transformation between GRS80 and IGN69 were used, as the geoid elevation varies of about $20 \mathrm{~cm}$ from one side of the lake to the other.

Students were tasked to create and make 3D adjustments of a local geodetic network of ten reference points, referenced from a IGN geodetic points, measured by total stations, and compensated by using a 3D least-square adjustment software.

\subsection{Topo-bathymetry surveys}

Before starting the camp, a particular attention has been undertaken in the calibration of the MBES (MultiBeam Echo-Sounder), the VML (Vessel Mounted LiDAR) and their Inertial Measurement Unit (IMU) to know precisely the boresight angles and lever arms between the various sensors. A special attention was devoted to the minimization of the TPU through very accurate instrument calibration.

The calibration of the VML/IMU was made in laboratory on a sphere scanned from several points of view in order to replicate the movements of roll, pitch and heading. Before the calibration, the VML and the IMU were installed on a permanent mounted bracket. The assembly remains the same for the transport of the instrument and when mounted on the boat. For calibration of the MBES, a patch test was conducted on the lake a few days before the beginning of the fieldwork.

To perform the topo-bathymetry surveys, the ENSTA Bretagne team had deployed their catamaran. The boat has a capacity of five persons on board including three workstations. One workstation was to control the sonar, the other for the VML and the last for the quality control in real-time. The boat was equipped with a MBES Kongsberg EM3002, from Boskalis, a VML Leica HDS6200 and a sidescan sonar (Figure 3 ). Mounted on a survey vessel, each component of the integrated system was coupled with an IMU 
(Ocatns 4 from IxSea). Robust geo-referencing and motion compensation enable the production of precise map of the lake from a combination of MBES and VML equipments.

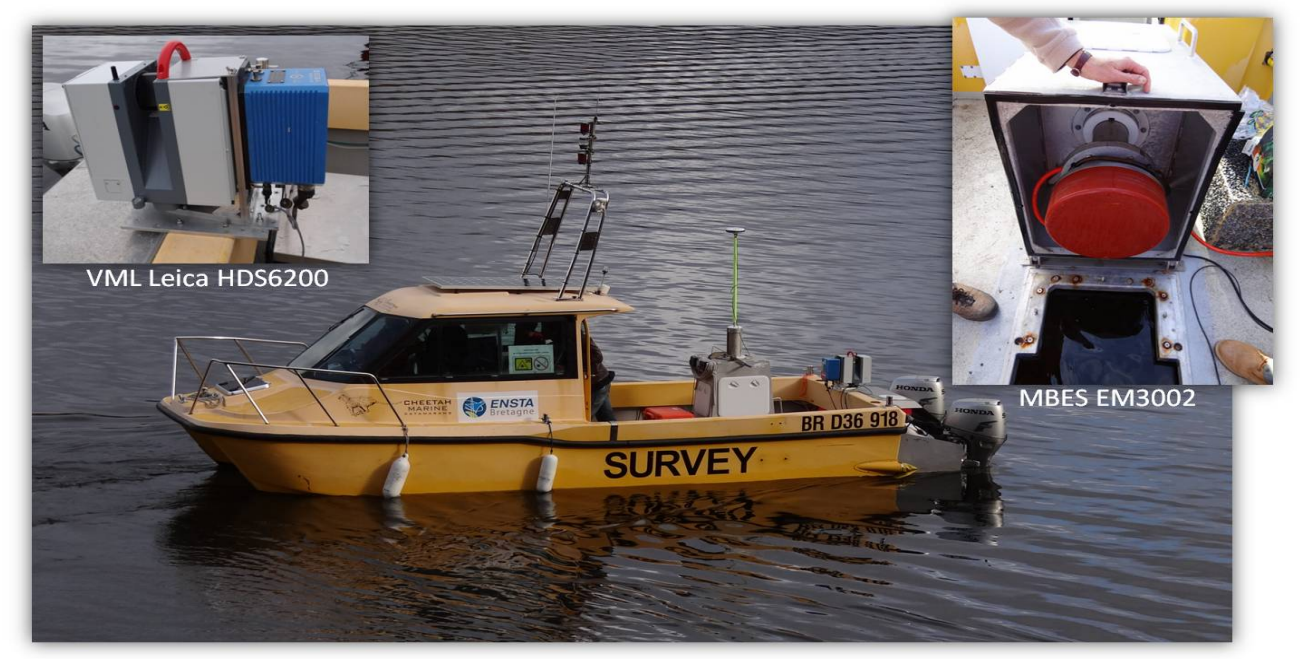

Figure 3: Topo-bathymetric works

For the land part of the fieldwork, students had access to several devices such as GPS, total stations and TLS (Figure 3).

\subsection{Data post-processing}

All VML and MBES data has been acquired by using the QPS/Qinsy software. Data were exported in xtf file format for processing under CARIS HIPS and SIPS. The main data post-processing tasks were to identify the presence of sound velocity profile problems, of wrong positioning data due to GPS multipaths and wrong soundings due to soft sediments. Quality checks, object detection, geo-referencing of obstructions, data cleaning have been also performed under the CARIS HIPS/SIPS environment.

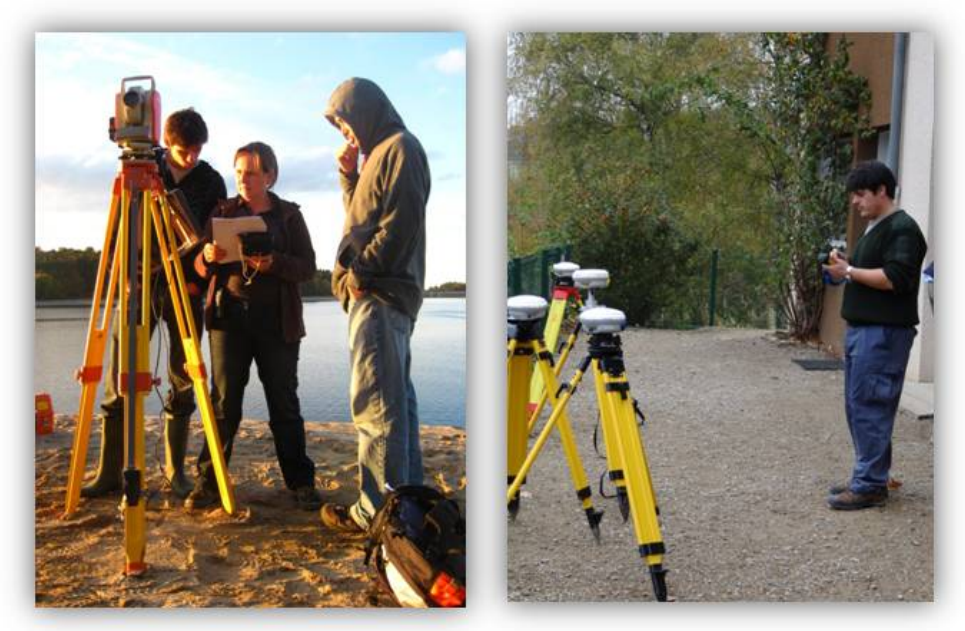

Figure 4: Land surveying works

\subsection{Infrastructure surveys}

An important part of the project was devoted to the dam and to the outflow inspection surveys. For these tasks, the staff imposed a TPU of $5 \mathrm{~cm}$. The infrastructures were surveyed with the VML and compared to a set of control points (Figure 5). TLS scans have also been performed, for the sake of comparison with VML data. 


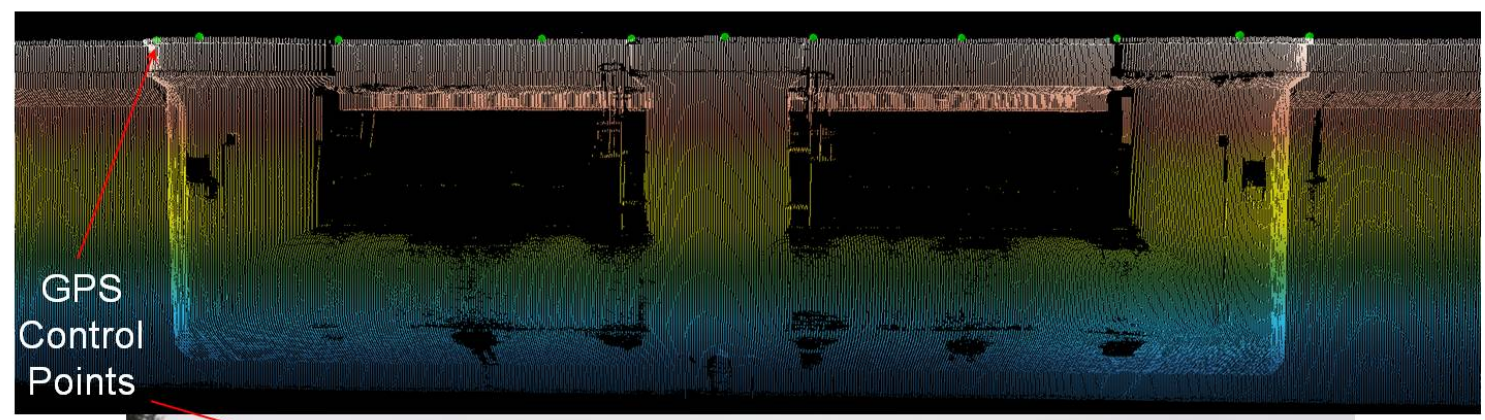

\subsection{Chart production}

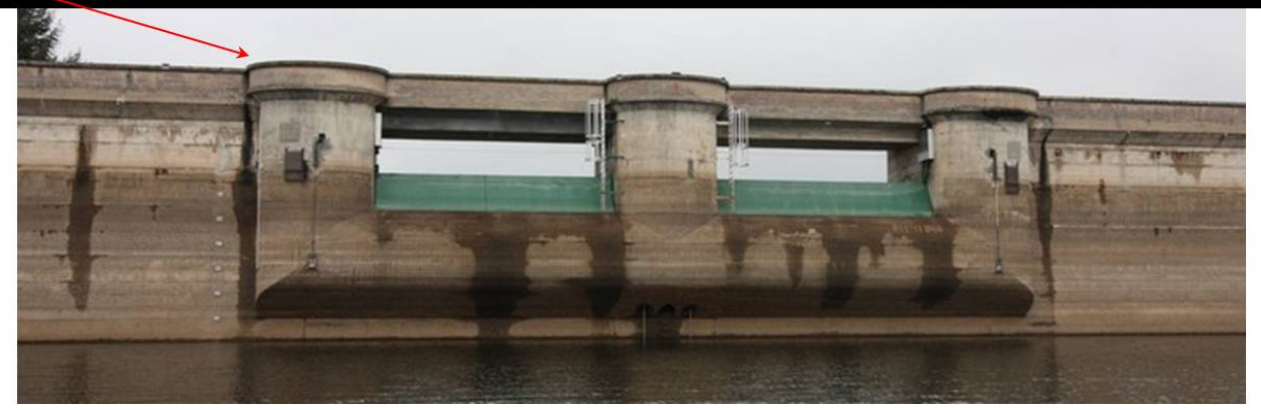

Figure 5: 3D view of the Vassivière dam, obtained from VML datasets

After the project, the students were tasked to create a nautical chart of the lake by using the CARIS S-57 Composer. They designed a chart devoted to safety of navigation, considering the importance of traffic on the lake during the summer. The result is a 1/10 000 compilation scale chart, referenced to the vertical datum 646m (IGN69). Coastline was determined by using VML data and topographic data. Obstructions have been identified in order to design safe isobaths.

Figure 6 :

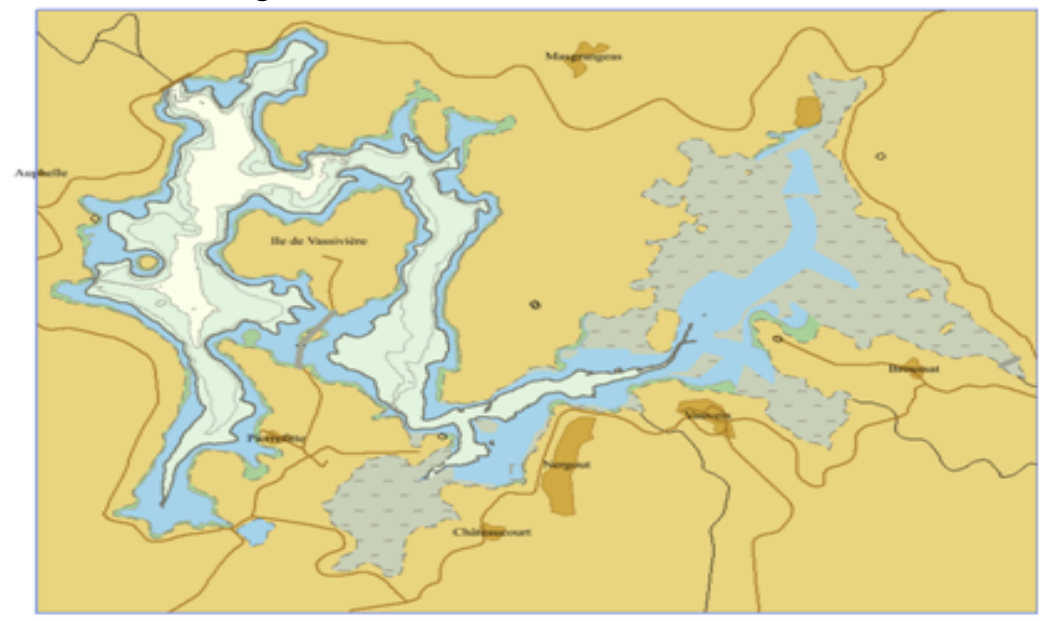

Nautical chart of

\section{Vassivière Lake, France}

\section{DISCUSSION}

\subsection{Interest of international cooperation}

The added value of an international cooperation for such a large survey training project lies in:

- The usage of a wide variety of equipment provided by the participating institutes;

- Student work in international teams, in an unknown location;

- The possibility of a large scale project, motivated by the industry (EDF); 
- A multidisciplinary team from several countries which allows us to plan a wide variety of fieldworks and post-processing activities.

\subsection{Interest of the project for the industry}

Due to the size of the project, its outcomes are subject to client approbation, therefore the industry contributes to student work evaluation. Our project has been sponsored by the Royal Boskalis Westminster company. They provided equipment for the project, visited the project location, made a presentation of the industry needs and made a feedback evaluation after the project. The conclusions from this evaluation were very positive and a company as like Boskalis has a clear interest in such large scale projects that are organized at an international level.

\section{CONCLUSION}

International cooperation for the education of hydrographer's added value is very high for the students, the staff and the industry. Such a large project is quite difficult to set-up and coordinate but offers the possibility to address a variety of topics in surveying and post-processing. Moreover, it allowed students to use and compare different equipments. The level of autonomy of Master 2 level students increased and they were able to produce high quality results that will be used for the management of the Lake of Vassivière. Moreover, the amount of data that we got from the lake could be used to feed research projects and as a basis for another project in the same area. Indeed, the Lake of Vassivière offers an ideal environment for hydrographer's education.

Special Thanks to Boskalis (Sponsor of this project), CARIS, QPS for providing free software licences, and EDF for help and assistance during the project.

\section{REFERENCES}

[1]D. DODD, G. JOHNSTON, A. HOGGARTH. The Economic Impact of Appropriate Education in Hydrography, 7th FIG Regional Conf.; Hanoi, Vietnam, Oct 2009.

[2]V. BODER, D. EGGE. Hydrographic Education (Cat A) at the Newly founded Hafencity University, Hamburg (HCU).6th FIG Regional Conf.; San José, Costa-Rica, Nov 2007.

[3]D. EGGE. Education and Training in Hydrography --- Status and Perspectives. International Symposium on Application of Marine Geophysical Data and Undersea Feature Names, Seoul, Korea 2009.

[4] J. GREENFELD. Surveying Body of Knowledge, FIG Congress, Sydney, Australia 2010.

[5] N. SEUBE, N. DEBESE, R. MOITIE. Hydrography at Master and IHO Cat-A Level at the ENSTABretagne, International Hydrographic Review, May 2011. 


\section{CONTACTS}

Nicolas Seube, Thomas Touzé, Nathalie Debese, Rodéric Moitié, Irvin Probst ENSTA Bretagne

2 rue François Verny

Brest

FRANCE

Tel. $+33(0) 298348888$

Fax $+33(0) 298348846$

Email: nicolas.seube@ensta-bretagne.fr

Web site: http://www.ensta-bretagne.fr

Maude Audet Morin

CIDCO

310, rue des Ursulines, C.P. 3300

Rimouski (Québec) G5L 3A1

CANADA

Tel. + 14187251732 \#1722

Fax +14187241401

Email: maude.audet-morin@cido.ca

Web site: www.cidco.ca

Volker Böder

HafenCity University Hamburg (HCU)

Hebebrandtr. 1

D - 22296 Hamburg

GERMANY

Tel. +49 (0)40428 275393

Email: volker.boeder@hcu-hamburg.de

Alain De Wulf

Ghent University

Geomatic Engineering, Surveying

Departement of Geography

Krigslaan 281, S8

B-9000 Gent, BELGIUM

Telephone: +32477664983

Email: Alain.DeWulf@UGent.be

Web site: http://geoweb.ugent.be/data-acquisition-3d 